\title{
Experimental Study of the Dynamics and Structure of Self-Sustaining Premixed Cool Flames Using a Counterflow Burner
}

\author{
Christopher B. Reuter, Sang Hee Won, Yiguang Ju \\ Department of Mechanical and Aerospace Engineering, Princeton University
}

\author{
*Corresponding Author \\ Christopher B. Reuter \\ Department of Mechanical and Aerospace Engineering \\ Princeton University \\ Princeton, NJ 08544, USA \\ Phone: +1609258 1411 \\ Email: cbreuter@princeton.edu
}

Keywords: Cool flame; Counterflow premixed flame; Ozone; Extinction limit; S-curve 


\title{
Experimental Study of the Dynamics and Structure of Self-Sustaining Premixed Cool Flames Using a Counterflow Burner
}

\author{
Christopher B. Reuter, Sang Hee Won, Yiguang Ju \\ Department of Mechanical and Aerospace Engineering, Princeton University
}

\begin{abstract}
Self-sustaining premixed cool flames are successfully stabilized in a dimethyl ether/oxygen counterflow burner through ozone addition, creating a new platform for the quantitative measurement of cool flame extinction limits, ignition limits, and structure as well as the validation of low-temperature chemical kinetic models. First, results show that stable premixed cool flames can exist over a broad region of equivalence ratios and strain rates, which allows for the ignition and extinction limits of both cool flames and hot flames to be measured at a variety of conditions. It is seen that at low fuel concentrations the cool flame extinction limit surpasses the hot flame extinction limit, providing experimental validation to previous numerical predictions. Furthermore, the experiments demonstrate that the cool flame speed's dependence on equivalence ratio is far weaker than that of near-limit hot flames. It is also found that a hysteresis exists between cool flames and hot flames near the hot flame extinction limit at low fuel concentrations. The examination of cool flame structure through planar laser-induced fluorescence reveals that the $\mathrm{CH}_{2} \mathrm{O}$ profile of the premixed cool flame is much thicker than its hot flame counterpart at the same fuel concentration, confirming the importance of $\mathrm{CH}_{2} \mathrm{O}$ as an important cool flame product. Numerical calculations based on a detailed chemical kinetic model are able to capture these various trends and show good qualitative agreement with the experimental results. The present experiments provide a new method to study premixed cool flames in a laboratory setting and to advance the fundamental understanding of low-temperature chemistry and near-limit flame dynamics.
\end{abstract}




\section{Introduction}

As part of the continued push for new internal combustion engines with higher efficiency and lower emissions, technologies such as homogeneous charge compression ignition (HCCI) and reactivity controlled compression ignition (RCCI) have been increasingly studied in recent years [1-5]. For these kinetically-controlled systems, combustion takes place at lean conditions and moderate temperatures, which in many cases are reached through a two-stage ignition process governed by both high-temperature and low-temperature chemistry. While the scientific understanding of conventional hot flames is well established, fundamental knowledge of cool flame dynamics and chemistry is still quite limited.

The first discovery of a cool flame took place centuries ago [6], and since then many studies have provided insight into the characteristics of the mysterious "pale blue flame" [7]. Of particular importance for internal combustion engines were experiments showing the connection between cool flames and engine knocking [8,9]. Recent investigations have even applied the cool flame to reduced gravity $[10,11]$ and microgravity settings [12-15]. Yet despite these studies and others involving cool flames using heated surfaces [16, 17], heated reactors [18, 19], and stirred reactors [20,21], it has been notably difficult to establish self-sustaining cool flames in order to examine their detailed structure, extinction limits, flammability limits, and other dynamics in a laboratory setting without flame-wall thermal coupling.

Recent numerical simulations [22] demonstrated that a well-defined premixed cool flame can propagate for a broad range of equivalence ratios below the flammability limit of a hot flame. However, there is no direct experimental data to support this finding due to the difficulty in experimentally establishing a self-sustaining cool flame. Although Foster and Pearlman [10, 11] measured cool flame speeds in a spherical chamber, the initial mixture temperature was so high that the mixture was partially oxidized in front of the flame, and as a result the flame was not propagating in a well-defined non-reacting mixture.

The main difficulty in sustaining cool flames is intrinsically tied to their slow chemistry at low temperatures and atmospheric pressure. The primary chain-branching pathway in lowtemperature oxidation involves the alkylperoxy radical isomerization reaction $\left(\mathrm{RO}_{2}=\mathrm{QOOH}\right)$ and subsequent breakdown into an oxygenated radical and two $\mathrm{OH}$ radicals [23]. In order to initiate this $\mathrm{RO}_{2}$ chemistry, the fuel radical ( $\mathrm{R}$ ) must first be obtained from the fuel molecule (RH) by H-abstraction. However, at low temperatures the active radical concentration is quite low, resulting in slow fuel induction chemistry. Moreover, increasing the temperature to promote induction chemistry also tends to increase the rates of reactions such as $\mathrm{H}_{2} \mathrm{O}_{2}(+\mathrm{M})=$ $\mathrm{OH}+\mathrm{OH}(+\mathrm{M})$, which leads to the establishment of a hot flame governed by high-temperature chemistry. Therefore, in order to create a stable cool flame, one must find a way to create a sizable initial radical pool without favoring the reactions associated with high-temperature chemistry. 
One solution to the difficulty of cool flame induction is the use of plasma-assisted combustion. While direct plasma discharge [24] will indeed produce a large initial radical pool and a stable cool flame, the complicated plasma-flame kinetic interactions make this setup difficult for detailed study. Upstream plasma discharge into pure oxygen, however, will create stable ozone molecules which can carry the $\mathrm{O}$ radicals necessary to ignite a cool flame. This avoids initiating additional reactions in the unburned mixture and thus creates a well-defined boundary condition for cross-validation between experiments and modeling. This method has recently been successful in creating self-sustaining cool diffusion flames [25] for which the extinction limits and flame structures were measured in a counterflow burner.

The objective of this study, therefore, is to create an experimental platform for producing self-sustaining premixed cool flames through ozone addition. An ozone-assisted counterflow burner is utilized to establish cool flames and to allow for the quantitative investigation of cool flame dynamics and structure through the measurement of extinction limits, ignition limits, and species profiles. Numerical simulations are also conducted to understand the experimental results and to assess the predictability of kinetic models for cool flames.

\section{Experiment}

An ozone-assisted counterflow burner has been chosen as the experimental platform for this study due to its quasi-one-dimensional geometry, lack of wall-flame interactions (essential due to the weak heat release associated with cool flames), well-defined flame strain rates and boundary conditions, and ease of optical access. The burner itself is the same one used in several previous counterflow studies [25-29], with nozzle diameters of $13 \mathrm{~mm}$. A simplified schematic of the setup for this experiment is shown in Fig. 1. The upper burner nozzle issues pure nitrogen, which is heated to $600 \mathrm{~K}$ to decompose the ozone in the premixture (supplied by the bottom burner) in order to trigger ignition of the cool flame. The oxidizer stream initially consists of pure (>99.9\%) oxygen at $300 \mathrm{~K}$, which passes through a non-equilibrium plasma ozone generator (Ozone Solutions, TG-20). The ozone generator employs a dielectric barrier discharge at $170 \mathrm{kPa}$, which produces a variety of species including $\mathrm{O}, \mathrm{O}_{3}, \mathrm{O}_{2}(\mathrm{v}), \mathrm{O}\left({ }^{1} \mathrm{D}\right)$, and $\mathrm{O}_{2}\left(a^{1} \Delta_{g}\right)$ [30]. Of these, however, only $\mathrm{O}_{3}$ is stable at $300 \mathrm{~K}$, and none of the other species produced has a lifetime longer than $20 \mathrm{~ms}$. As a result, by the time the oxidizer stream encounters the fuel stream, only $\mathrm{O}_{2}$ and $\mathrm{O}_{3}$ are present. After the fuel stream is mixed in, the $\mathrm{O}_{2} / \mathrm{O}_{3} / \mathrm{DME}$ premixture is finally directed to the bottom burner exit. In this experiment, DME is chosen over other fuels for several reasons. It is gaseous at room temperature (heating the premixture would prematurely decompose the ozone), possesses fairly strong low-temperature chemistry, already has several detailed kinetic models of its oxidation, and its flame speeds at 1 atm have been well studied [31, 32].

The ozone concentration in the oxidizer stream was measured by an absorption spectroscopy method similar to the ones used in [25] and [30] and showed a dependence on the 

ozone generator to capture a range of wavelengths $(280-310 \mathrm{~nm})$ emitted by a Deuterium lamp (Oriel). The absorption spectra with the generator on and off were then compared to quantify the ozone concentration. Measurements were also performed at the burner exit to confirm that no ozone was lost as the premixture moved through the burner. For the range of oxygen flow rates in this study, the ozone concentration in the oxidizer remained between $3.0-3.4 \%$.

For all experiments in this study, the burner separation distance is set to $2.25 \mathrm{~cm}$. The strain rate $(a)$ is defined as the density-weighted gradient of the axial flow velocities [26-28, 33], specifically,

$$
a=2\left(\frac{U_{\text {lower }}}{L}\right)\left(1+\frac{U_{\text {upper }} \sqrt{\rho_{\text {upper }}}}{U_{\text {lower }} \sqrt{\rho_{\text {lower }}}}\right)
$$

where $U_{\text {upper }}$ and $U_{\text {lower }}$ are the velocities at the upper and lower burner exits, $\rho_{\text {upper }}$ and $\rho_{\text {lower }}$ are the mixture densities at the same exits, and $L$ is the burner separation distance. Additionally, the equivalence ratio $(\phi)$ is defined as the ratio of the total moles of fuel (DME) to total moles of oxidizer $\left(\mathrm{O}_{2}+\mathrm{O}_{3}\right)$ divided by the stoichiometric ratio. Mass flow rates of $\mathrm{N}_{2}, \mathrm{O}_{2}$, and DME are controlled through sonic nozzles calibrated to pressure gauges (Cecomp Electronics). All measurements are taken at atmospheric pressure (1 atm).

In order to visualize the premixed cool flame structure, planar laser-induced fluorescence (PLIF) of $\mathrm{CH}_{2} \mathrm{O}$ molecules is performed [34]. The third harmonic (355 nm) of an Nd:YAG laser (Quantel, Q-smart 850) excites the $\mathrm{CH}_{2} \mathrm{O}$ at an energy of approximately $200 \mathrm{~mJ} / \mathrm{pulse}$. Two band filters, passing frequencies between 400 and $450 \mathrm{~nm}$, are positioned in front of an ICCD camera (Princeton Instruments, PI-MAX 4) to isolate the $\mathrm{CH}_{2} \mathrm{O}$ fluorescence. The laser beam is expanded into a $200-\mu \mathrm{m}$-thick vertical sheet and positioned at the centerline of the burner.

For comparison with the experimental results, the numerical calculations in this paper are carried out using a modified PREMIX code [35] of the CHEMKIN package with an improved arc-length continuation method [36]. Dynamic flame behaviors (extinction limits, ignition limits, etc.) are simulated with a potential flow assumption, while detailed calculations of flame structure (species profiles) use a plug flow assumption. For DME oxidation, the kinetic mechanism of Zhao et al. [37] is employed with an update from Liu et al. [32]. The ozone reactions are primarily those of Ombrello et al. [30] (with the original rate constants taken from [38]) with an update of the ozone decomposition rate [39]. All numerical calculations are performed with the assumption of $3 \%$ ozone in the oxidizer stream. While the experimental ozone concentration does vary from 3.0-3.4\%, a sensitivity study (given in Appendix A) shows that the trends in flame behavior are qualitatively the same within this range. Across these ozone concentrations, the extinction limits remain within $\pm 10 \%$, and the hot flame extinction-cool flame extinction crossover point does not change from $\phi=0.097$. 


\section{Results and discussion}

The ozone-assisted counterflow burner setup was successful in establishing selfsustaining premixed cool flames. The cool flame seemed most prone to auto-ignite at lower strain rates, usually in the vicinity of $a=60 \mathrm{~s}^{-1}$ and $\phi=0.1$. A direct photograph of a $\mathrm{DME} / \mathrm{O}_{2} / \mathrm{O}_{3}$ premixed cool flame at an equivalence ratio of $\phi=0.114$ and a strain rate of $a=89$ $\mathrm{s}^{-1}$ is shown in Fig. 2a. The cool flame is dim but still clearly visible in a dark room. Ozone was absolutely necessary for the premixed cool flame to remain self-sustaining at this experimental condition, as the stable cool flame would immediately extinguish if the ozone generator was switched off. A path flux analysis performed at this condition gives a quantitative idea of the importance of ozone. The DME fuel molecules feeding the cool flame are nearly always (>96\%) decomposed through $\mathrm{H}$-abstraction reactions by either $\mathrm{O}$ or $\mathrm{OH}$ radicals. $\mathrm{O}$ radicals are almost exclusively ( $>97 \%$ ) produced from $\mathrm{O}_{3}$ molecules through the reactions $\mathrm{O}_{3}+\mathrm{O}_{2} \rightarrow \mathrm{O}_{2}+\mathrm{O}+\mathrm{O}_{2}$, $\mathrm{O}_{3}+\mathrm{N}_{2} \rightarrow \mathrm{O}_{2}+\mathrm{O}+\mathrm{N}_{2}$, and $\mathrm{O}_{3}+\mathrm{O}_{3} \rightarrow \mathrm{O}_{2}+\mathrm{O}+\mathrm{O}_{3}$. Furthermore, 42\% of $\mathrm{OH}$ radicals are produced from reactions involving $\mathrm{O}$ or $\mathrm{O}_{3}$, primarily though $\mathrm{CH}_{3} \mathrm{OCH}_{3}+\mathrm{O}=\mathrm{CH}_{3} \mathrm{OCH}_{2}+\mathrm{OH}$, $\mathrm{O}_{3}+\mathrm{H} \rightarrow \mathrm{OH}+\mathrm{O}_{2}$, and $\mathrm{CH}_{2} \mathrm{O}+\mathrm{O}=\mathrm{HCO}+\mathrm{OH}$. Therefore, the removal of ozone would indeed result in a tremendous reduction in the active radical pool and the initial fuel decomposition rate. This dependence on ozone addition contrasts the cool n-heptane diffusion flames in [25], which became dimmer but could remain self-sustaining without ozone. While calculations from [22] and [40] indicate that heating the $\mathrm{DME} / \mathrm{O}_{2}$ premixture to about $500 \mathrm{~K}$ may allow for the establishment of premixed cool flames without ozone sensitization, this method was not tested due to the much lower strain rates $\left(\sim 30 \mathrm{~s}^{-1}\right)$ required, which can be difficult to maintain at atmospheric conditions.

For many of the test cases, a conventional hot flame is also able to be established at identical flow and mixture conditions as the cool flame by simply igniting the stable cool flame with a conventional stove ignitor. Figure $2 \mathrm{~b}$ shows a hot flame at the same equivalence ratio $(\phi$ $=0.114)$ and strain rate $\left(a=89 \mathrm{~s}^{-1}\right)$ as the cool flame in Fig. 2a. The hot flames were not only noticeably brighter than their cool flames counterparts but also stabilized closer toward the bottom burner (premixture side), indicating a higher flame speed.

\subsection{Observations of flame limits and dynamics}

One question addressed in this study is whether a cool flame can remain stable beyond the extinction limit of a hot flame, as predicted in [22]. The stable regions of cool flames and hot flames for a mixture in a counterflow burner can be explained in terms of the classic S-curve of flame temperature versus strain rate. Figure 3 shows the calculated S-curve at the same equivalence ratio $(\phi=0.114)$ as the flames in Figs. 2a and 2b. Each of the turning points in the curve represents a specific flame limit. On the upper (hot flame) branch, the hot flame extinction (HFE) limit indicates the highest strain rate the hot flame can sustain, beyond which it will extinguish into an unburned mixture (with $T_{\max }=600 \mathrm{~K}$, the boundary condition at the upper 

the cool flame can sustain before extinguishing. The stable portion of the cool flame branch also has a minimum strain rate limit, below which high-temperature ignition (HTI) will occur and the cool flame will directly transition into a stable hot flame. The numerical calculations indicate that accelerated $\mathrm{H}_{2} \mathrm{O}_{2}$ decomposition into $\mathrm{OH}$ radicals is the primary reason for this second-stage ignition transition. Finally, the low-temperature ignition (LTI) point represents the minimum strain rate of the unburned mixture before auto-ignition will occur. Figure 3 shows that for a fairly wide range of strain rates (between HTI at $a=67 \mathrm{~s}^{-1}$ and CFE at $a=150 \mathrm{~s}^{-1}$ for $\phi=0.114$ ), both stable cool flames and stable hot flames can be observed. This result agrees with the experimental observation of both a cool flame and a hot flame at the same conditions in Figs. 2a and $2 b$.

To examine the variability in the extinction limits of hot flames and cool flames in a strained flow, the mixture equivalence ratio is varied and the ignition-to-extinction S-curves are compared. Figure 4 shows the calculated S-curves for equivalence ratios of $\phi=0.114$ (the same as in Fig. 3), $\phi=0.095$, and $\phi=0.080$. It is interesting that as the equivalence ratio is lowered, the stable cool flame branch shifts to lower strain rates but remains essentially the same width (approximately $85 \mathrm{~s}^{-1}$ between HTI and CFE). However, the effect of equivalence ratio on the hot flame branch and its extinction limit is much greater. While the CFE limit falls from $a=150$ $\mathrm{s}^{-1}$ at $\phi=0.114$ to $a=109 \mathrm{~s}^{-1}$ at $\phi=0.080$, the HFE limit has a more pronounced drop from $a=$ $281 \mathrm{~s}^{-1}$ to $a=50 \mathrm{~s}^{-1}$ over the same range. This result suggests that high-temperature reactions have larger activation energies than low-temperature reactions and that the reaction mechanisms governing high-temperature flames are more sensitive to flame temperature than the cool flame reaction mechanisms.

Most interestingly, Figure 4 shows that at low equivalence ratios the CFE limit can exceed the HFE limit. In these cases, the hot flame will not extinguish into an unburned mixture but transition into a stable, self-sustaining cool flame. Lighting the post-HFE cool flame with a stove ignitor (a high-temperature butane flame) does not result in re-ignition to a $\mathrm{DME} / \mathrm{O}_{2} / \mathrm{O}_{3}$ hot flame; instead, it remains a cool flame and experiences no regime change. The cool flame will continue to burn unless the strain rate is further increased beyond the CFE limit. This calls into question the conventional definition of the extinction limit for strained flames (which usually only considers the HFE limit), similar to how numerical results from [22] questioned the meaning of the flammability limit for freely-propagating premixed cool flames.

A regime diagram for hot and cool $\mathrm{DME} / \mathrm{O}_{2} / \mathrm{O}_{3}$ premixed flames, including both numerical (S-curve) and experimental results, is depicted in Fig. 5. Four main regimes can be defined: a region of no flames (I), a purely cool flame region (II), a region where both cool flames and hot flames can exist (III), and a purely hot flame region (IV). For instance, at a global strain rate of $a=89 \mathrm{~s}^{-1}$, no flames of any kind were observed in the experiment at equivalence ratios $\phi<0.086$. Between $\phi=0.086$ (CFE) and $\phi=0.10$ (HFE), only cool flames 
were stable, giving experimental support to the numerical prediction in Fig. 4 that at low equivalence ratios a cool flame can propagate beyond the extinction limit of a hot flame. At equivalence ratios $0.10<\phi<0.176$, both cool flames and hot flames were able to be established. For $\phi>0.176$ (HTI), only hot flames were observed, as any cool flame would quickly transform to a hot flame. Therefore, both the mixture equivalence ratio and the flow strain rate can have significant impacts on the flame regime.

Numerical calculations based upon the Zhao et al. [37] chemical kinetic model emulate the experimental regimes of Fig. 5 fairly well from a qualitative standpoint. At lower equivalence ratios, both experiments and modeling show that cool flames can remain stable beyond the extinction limit of hot flames. In this region, the definition of the conventional extinction limit is no longer valid, and an extended flame extinction limit incorporating the CFE limit is necessary. At higher equivalence ratios $(\phi>0.097)$, numerical simulations show that the flame temperature is high enough that a high-temperature flame can be sustained beyond the extinction limit of the cool flame. In this region, the conventional extinction limit definition is adequate. Overall, while the numerical model slightly overpredicts the extinction and ignition limits, it captures the dynamic trends qualitatively well.

Figure 6 depicts the hysteresis possible between hot flames and cool flames at low equivalence ratios (in this case, $\phi=0.080$ ), confirmed by experimental observations. Beginning on the lower branch of the S-curve, a stable cool flame can exist for any strain rate between the CFE limit and HTI. At HTI, the cool flame directly transitions into a stable hot flame. The hot flame remains stable for all strain rates below the HFE limit (until flashback). If the strain rate is increased beyond the HFE limit, the hot flame directly transitions back into a stable cool flame, closing the loop.

This hysteresis cycle was confirmed in counterflow experiments by adding a bleed valve to the $\mathrm{DME} / \mathrm{O}_{2} / \mathrm{O}_{3}$ premixture. At full flow (no bleed, highest strain rate), a cool flame was stabilized far from the bottom burner. As the premixture was bled off (strain rate lowered at constant equivalence ratio), the cool flame moved toward the bottom burner due to the decrease in flow velocity and unchanging flame speed. After a certain amount of flow was bled off, the cool flame transitioned to a hot flame and moved even closer to the bottom burner as a result of the hot flame's higher flame speed. When the bleed was lessened (strain rate increased at constant equivalence ratio), the hot flame retreated from the bottom burner due to the now increasing flow velocity. Finally, nearing full flow again, the hot flame transitioned back into a stable cool flame at the HFE limit.

In order to explore the chemical kinetics behind this behavior more deeply, rate constant sensitivity analyses were performed and are summarized in Fig. 7. The four conditions (LTI, HTI, CFE, HFE) in the sensitivity analysis correspond to the four turning points in Fig. 6. A sharp contrast exists between the reactions most influential on the low-temperature ignition (LTI) 
and high-temperature ignition (HTI) strain rates. For LTI, the decomposition of ozone to form $\mathrm{O}$ radicals is the dominant reaction, as it creates the initial radical pool to begin low-temperature fuel decomposition. The production of the fuel radical through $\mathrm{H}$-abstraction of the fuel molecule $\left(\mathrm{CH}_{3} \mathrm{OCH}_{3}+\mathrm{OH}=\mathrm{CH}_{3} \mathrm{OCH}_{2}+\mathrm{H}_{2} \mathrm{O}\right)$ is also important. Furthermore, there is a competition between the alkylperoxy radical isomerization reaction $\left(\mathrm{CH}_{3} \mathrm{OCH}_{2} \mathrm{O}_{2}=\right.$ $\mathrm{CH}_{2} \mathrm{OCH}_{2} \mathrm{O}_{2} \mathrm{H}$, alternatively written as $\mathrm{RO}_{2}=\mathrm{QOOH}$ ), which is part of a chain-branching sequence, and $\mathrm{RO}_{2}+\mathrm{RO}_{2}$, which is chain-terminating due to the creation of three stable products. However, for HTI, these fuel decomposition reactions are comparatively much less important. Instead, one can see that the classic high-temperature chemistry reactions involving small species dominate. The branching reaction $\mathrm{H}+\mathrm{O}_{2}=\mathrm{O}+\mathrm{OH}$ competes with $\mathrm{H}+\mathrm{O}_{2}(+\mathrm{M})$ $=\mathrm{HO}_{2}(+\mathrm{M}), \mathrm{H}_{2} \mathrm{O}_{2}$ decomposition stimulates ignition through its production of $\mathrm{OH}$ radicals, and $\mathrm{CO}$ oxidation correlates positively with HTI due to its high exothermicity.

Likewise, substantial differences are evident between the key reactions affecting the cool flame extinction (CFE) and hot flame extinction (HFE) strain rates. CFE is primarily defined by the competition between the two main consumption pathways of $\mathrm{QOOH}$ radicals $\left(\mathrm{CH}_{2} \mathrm{OCH}_{2} \mathrm{O}_{2} \mathrm{H}\right)$. The reaction $\mathrm{CH}_{2} \mathrm{OCH}_{2} \mathrm{O}_{2} \mathrm{H}+\mathrm{O}_{2}=\mathrm{O}_{2} \mathrm{CH}_{2} \mathrm{OCH}_{2} \mathrm{O}_{2} \mathrm{H}$ is part of the lowtemperature chain-branching sequence that eventually leads to the production of two $\mathrm{OH}$ radicals. The other reaction, $\mathrm{CH}_{2} \mathrm{OCH}_{2} \mathrm{O}_{2} \mathrm{H}=\mathrm{OH}+\mathrm{CH}_{2} \mathrm{O}+\mathrm{CH}_{2} \mathrm{O}$, produces a single $\mathrm{OH}$ radical and is therefore only chain-propagating. A few other reactions important to the lowtemperature chain-branching sequence (namely, $\mathrm{R}$ production and $\mathrm{QOOH}$ production) also have a noticeable effect on CFE. In contrast, HFE depends most strongly upon CO oxidation and the two competing $\mathrm{H}+\mathrm{O}_{2}$ reactions. For a very lean flame such as the $\phi=0.080$ one analyzed in Figs. 6 and 7, this difference is particularly interesting. The most sensitive reaction for HFE (CO $\left.+\mathrm{OH}=\mathrm{CO}_{2}+\mathrm{H}\right)$ is quite temperature-dependent, and as a result the hot flame extinguishes before the strain rate reaches $50 \mathrm{~s}^{-1}$ due to the low flame temperature of $\sim 1250 \mathrm{~K}$. On the other hand, the reaction rate for $\mathrm{CH}_{2} \mathrm{OCH}_{2} \mathrm{O}_{2} \mathrm{H}+\mathrm{O}_{2}=\mathrm{O}_{2} \mathrm{CH}_{2} \mathrm{OCH}_{2} \mathrm{O}_{2} \mathrm{H}$ (which most strongly correlates with $\mathrm{CFE}$ ) does not depend on temperature, and the cool flame is not predicted to extinguish until $a=110 \mathrm{~s}^{-1}$.

This new understanding of near-limit flame dynamics has important implications for fire safety, particularly in high-oxygen environments. Based on the above experiments, it is possible to extinguish a hot flame well past the HFE limit, have it remain burning as a dim cool flame, and then regain the hot flame once the strain rate has been relaxed, without even the need for a spark. Because of this resilient characteristic of fuels with strong low-temperature chemistry, it is unwise to plan fire safety procedures with only their hot flame limits considered. Nayagam [12] reported a similar concern when studying cool diffusion flames of $n$-heptane droplets in microgravity experiments.

\subsection{Planar laser-induced fluorescence measurements}


In addition to the above observations of premixed cool flame dynamics, measurements of the flame structure were also performed through $\mathrm{CH}_{2} \mathrm{O}$ PLIF. Figures $8 \mathrm{a}$ and $8 \mathrm{~b}$ reveal the raw PLIF images of a cool flame and hot flame, respectively, at the same conditions as the flames in the direct photographs in Figs. $2 \mathrm{a}$ and $2 \mathrm{~b}\left(\phi=0.114, a=89 \mathrm{~s}^{-1}\right)$. The cool flame's $\mathrm{CH}_{2} \mathrm{O}$ signal profile is significantly thicker than that of the hot flame, with a full width at half maximum four times larger at the centerline. This agrees well with numerical calculations that show $\mathrm{CH}_{2} \mathrm{O}$ (along with $\mathrm{CO}$ and $\mathrm{H}_{2} \mathrm{O}$ ) as one of the most important cool flame products. For the hot flame, $\mathrm{CH}_{2} \mathrm{O}$ is primarily an intermediate that is decomposed at the beginning of the main heat release period.

To compare these results to numerical simulations, the PLIF intensities at the burner centerline for the cool flame and hot flame from Figs. 8a and 8b are depicted in Fig. 9a. Numerical simulations of the $\mathrm{CH}_{2} \mathrm{O}$ mole fraction at these conditions, shown in Fig. 9b, exhibit similar trends to the experiments, as the cool flame's $\mathrm{CH}_{2} \mathrm{O}$ profile is once again several times thicker than the hot flame's. However, the simulations do underpredict the flame location (flame speed) of both the cool flame and hot flame at these conditions. Although the maximum hot flame $\mathrm{CH}_{2} \mathrm{O}$ PLIF signal (less than half of the cool flame PLIF signal) and the maximum hot flame $\mathrm{CH}_{2} \mathrm{O}$ mole fraction prediction (essentially equal to the cool flame mole fraction) also disagree, the PLIF results were not adjusted for differences in quenching at low and high temperatures, which may account for some of the discrepancy. Figure $9 \mathrm{~b}$ also numerically compares the heat release rates between cool and hot flames. The peak heat release rate of the cool flame is smaller than the hot flame's by a factor of 6 . In case of the hot flame, most of heat is produced from the reactions associated with $\mathrm{OH}$ radical consumption (e.g., $\mathrm{CO}+\mathrm{OH}=\mathrm{CO}_{2}+$ $\mathrm{H}$ and $\mathrm{HO}_{2}+\mathrm{OH}=\mathrm{H}_{2} \mathrm{O}+\mathrm{O}_{2}$ ), whereas in the cool flame a large portion of the heat release is from low-temperature fuel radical reactions (e.g., $\mathrm{R}+\mathrm{O}_{2}=\mathrm{RO}_{2}$ and $\mathrm{RH}+\mathrm{OH}=\mathrm{R}+\mathrm{H}_{2} \mathrm{O}$ ).

As the equivalence ratio decreases and the flame moves into the purely cool flame regime, it can be seen that the cool flame structure changes only slightly. Figure 10 shows the centerline PLIF intensity of a cool flame at the same strain rate $\left(a=89 \mathrm{~s}^{-1}\right)$ as the flames in Fig. $9 \mathrm{a}$ but at a lower equivalence ratio $(\phi=0.088)$. At this condition, the hot flame is past its extinction limit, which corresponds to region II of Fig. 5. Compared to the $\phi=0.114$ cool flame, the $\phi=0.088 \mathrm{cool}$ flame has a $\mathrm{CH}_{2} \mathrm{O}$ PLIF signal with a maximum at nearly the same location ( $0.9 \mathrm{~mm}$ further from the bottom burner) but $56 \%$ smaller. The full widths at half maximum are also comparable (3.2 mm in Fig. 9a versus $2.5 \mathrm{~mm}$ in Fig. 10). Furthermore, numerical simulations of the two cool flames agree with these slight structural changes. The $\mathrm{CH}_{2} \mathrm{O}$ mole fraction of the lean $(\phi=0.088)$ cool flame peaks $0.2 \mathrm{~mm}$ further from the bottom burner than the rich one, and the maximum value decreases by $53 \%$.

In order to observe further the equivalence ratio dependencies of both cool and hot flames, $\mathrm{CH}_{2} \mathrm{O}$ PLIF measurements are taken at a variety of equivalence ratios and strain rates. Since the ozone concentration is sensitive to the oxygen flow rate, the oxygen flow rate is 

of momentum between the upper and lower burners at certain conditions. In case of $a=89 \mathrm{~s}^{-1}$ (momentum balanced) in Fig. 11, the stagnation plane is located very near the midpoint of the two nozzles. For the other conditions at $a=76$ and $58 \mathrm{~s}^{-1}$, the momentum is imbalanced, and the stagnation planes are biased toward the upper burner.

From Figure 11, it can be seen that the location of the cool flame (defined by the maximum centerline $\mathrm{CH}_{2} \mathrm{O}$ signal) shows little sensitivity to the equivalence ratio, with only small changes in position during the sweeps in $\phi$ at constant strain rate. Since the flow velocity is not changing at constant strain rate, the cool flame speed must have a fairly weak dependence on the equivalence ratio at these conditions. The hot flame, on the other hand, shows significant movement for even small changes in equivalence ratio, which supports the well-known strong correlation between hot flame speed and equivalence ratio.

Numerical calculations agree with both of these trends and give insight into some of the underlying factors behind them-in particular, the thermal effects (flame temperature) and kinetic effects (radical pool size) that drive flame propagation. For the hot flame, the maximum flame temperature decreases from $1684 \mathrm{~K}$ to $1463 \mathrm{~K}$ when the equivalence ratio is lowered from $\phi=0.114$ to $\phi=0.095$ at a strain rate of $a=89 \mathrm{~s}^{-1}$. Furthermore, the radical pool (defined by the sum of the maximum $\mathrm{O}, \mathrm{H}$, and $\mathrm{OH}$ radical concentrations) drops from $8100 \mathrm{ppm}$ to $3400 \mathrm{ppm}$. Because of these two factors, the hot flame suffers a substantial decrease in propagation speed as the equivalence ratio falls. On the other hand, the cool flame sees a temperature decrease from only $910 \mathrm{~K}$ to $875 \mathrm{~K}$ and a slight radical pool increase from $19 \mathrm{ppm}$ to $21 \mathrm{ppm}$ over the same period. Together, these opposing thermal effects and kinetic effects result in a very weak dependence of cool flame speed on the equivalence ratio.

\section{Conclusion}

The establishment of stable, self-sustaining premixed cool flames in a laboratory setting has been experimentally demonstrated by using a counterflow burner setup in combination with an ozone generator. The dim cool flames exhibit different flame dynamics than their brightly burning hot flame counterparts, particularly the weaker dependence of the cool flame extinction limit on equivalence ratio. These dynamic observations have been organized into a premixed cool flame regime diagram with regions of unburned mixtures, purely cool flames, purely hot flames, and both cool and hot flames. An extended flame extinction limit incorporating the hot extinction limit at higher equivalence ratios and the cool flame extinction limit at lower equivalence ratios has been suggested. Furthermore, both numerical modeling and experimental observations reveal the possibility of hysteresis between hot flames and cool flames under certain conditions, which could have important implications for fire safety in high-oxygen environments. Finally, planar laser-induced fluorescence measurements show the increased $\mathrm{CH}_{2} \mathrm{O}$ profile of cool flames and the indifference of the cool flame speed to equivalence ratio. 
The results of this experiment can be used as a foundation for future studies of premixed cool flames. Despite how common cool flames are as part of the two-stage ignition process in many engines, there is still much to learn about their detailed structure and chemistry.

\section{Acknowledgements}

The authors recognize the support of NASA ISS Post-Graduate award NNX15AB67G, NSF grant CBET-1507358, AFOSR grant FA9550-13-1-0119, and the Department of Defense's National Defense Science and Engineering Graduate Fellowship program. 


\section{References}

[1] J.E. Dec, Advanced compression-ignition engines - understanding the in-cylinder processes, Proc. Combust. Inst. 32 (2009) 2727-2742.

[2] S.L. Kokjohn, R.M. Hanson, D.A. Splitter, R.D. Reitz, Fuel reactivity controlled compression ignition (RCCI): a pathway to controlled high-efficiency clean combustion, Int. J. Engine Res. 12 (2011) 209-226.

[3] A.B. Dempsey, N.R. Walker, E. Gingrich, R.D. Reitz, Comparison of low temperature combustion strategies for advanced compression ignition engines with a focus on controllability, Combust. Sci. Technol. 186 (2013) 210-241.

[4] S. Saxena, I.D. Bedoya, Fundamental phenomena affecting low temperature combustion and HCCI engines, high load limits and strategies for extending these limits, Prog. Energy Combust. Sci. 39 (2013) 457-488.

[5] R.D. Reitz, G. Duraisamy, Review of high efficiency and clean reactivity controlled compression ignition (RCCI) combustion in internal combustion engines, Prog. Energy Combust. Sci. 46 (2015) 12-71.

[6] H. Davy, Some new experiments and observations on the combustion of gaseous mixtures, with an account of a method of preserving a continued light in mixtures of inflammable gases and air without flame, Phil. Trans. R. Soc. Lond. 107 (1817) 77-83.

[7] W.H. Perkin, Some observations on the luminous incomplete combustion of ether and other organic bodies, J. Chem. Soc. 41 (1882) 363-367.

[8] D.T.A. Townend, Ignition regions of hydrocarbons, Chem. Rev. 21 (1937) 259-278.

[9] P.R. Ballinger, P.R. Ryason, Isolated stable cool flames of hydrocarbons, Symp. (Int.) Combust. 13 (1971) 271-277.

[10] M. Foster, H. Pearlman, Cool flames at terrestrial, partial, and near-zero gravity, Combust. Flame 147 (2006) 108-117.

[11] M. Foster, H. Pearlman, Cool flame propagation speeds, Combust. Sci. Technol. 179 (2007) 1349-1360.

[12] V. Nayagam, D.L. Dietrich, P.V. Ferkul, M.C. Hicks, F.A. Williams, Can cool flames support quasi-steady alkane droplet burning?, Combust. Flame 159 (2012) 3583-3588.

[13] T.I. Farouk, F.L. Dryer, Isolated n-heptane droplet combustion in microgravity: ' CCool Flames" - Two-stage combustion, Combust. Flame 161 (2014) 565-581.

[14] T.I. Farouk, M.C. Hicks, F.L. Dryer, Multistage oscillatory "Cool Flame" behavior for isolated alkane droplet combustion in elevated pressure microgravity condition, Proc. Combust. Inst. 35 (2015) 1701-1708.

[15] V. Nayagam, D.L. Dietrich, M.C. Hicks, F.A. Williams, Cool-flame extinction during nalkane droplet combustion in microgravity, Combust. Flame 162 (2015) 2140-2147.

[16] H.J. Emeleus, The spectra of the phosphorescent flames of carbon disulphide and ether, J. Chem. Soc. 129 (1926) 2948-2951.

[17] L.R. Cairnie, A.J. Harrison, P.A. Morgan, Autoignition in a free convection boundary layer, Symp. (Int.) Combust. 18 (1981) 1799-1806.

[18] H. Oshibe, H. Nakamura, T. Tezuka, S. Hasegawa, K. Maruta, Stabilized three-stage oxidation of DME/air mixture in a micro flow reactor with a controlled temperature profile, Combust. Flame 157 (2010) 1572-1580.

[19] S. Kikui, T. Kamada, H. Nakamura, T. Tezuka, S. Hasegawa, K. Maruta, Characteristics of n-butane weak flames at elevated pressures in a micro flow reactor with a controlled temperature profile, Proc. Combust. Inst. 35 (2015) 3405-3412. 

[21] J.F. Griffiths, T. Inomata, Oscillatory cool flames in the combustion of diethyl ether, J. Chem. Soc. Faraday Trans. 88 (1992) 3153-3158.

[22] Y. Ju, C.B. Reuter, S.H. Won, Numerical simulations of premixed cool flames of dimethyl ether/oxygen mixtures, Combust. Flame 162 (2015) 3580-3588.

[23] J. Zádor, C.A. Taatjes, R.X. Fernandes, Kinetics of elementary reactions in low-temperature autoignition chemistry, Prog. Energy Combust. Sci. 37 (2011) 371-421.

[24] W. Sun, S.H. Won, T. Ombrello, C. Carter, Y. Ju, Direct ignition and S-curve transition by in situ nano-second pulsed discharge in methane/oxygen/helium counterflow flame, Proc. Combust. Inst. 34 (2013) 847-855.

[25] S.H. Won, B. Jiang, P. Diévart, C.H. Sohn, Y. Ju, Self-sustaining n-heptane cool diffusion flames activated by ozone, Proc. Combust. Inst. 35 (2015) 881-888.

[26] S.H. Won, W. Sun, Y. Ju, Kinetic effects of toluene blending on the extinction limit of ndecane diffusion flames, Combust. Flame 157 (2010) 411-420.

[27] S.H. Won, S. Dooley, F.L. Dryer, Y. Ju, Kinetic effects of aromatic molecular structures on diffusion flame extinction, Proc. Combust. Inst. 33 (2011) 1163-1170.

[28] S.H. Won, S. Dooley, F.L. Dryer, Y. Ju, A radical index for the determination of the chemical kinetic contribution to diffusion flame extinction of large hydrocarbon fuels, Combust. Flame 159 (2012) 541-551.

[29] J.K. Lefkowitz, S.H. Won, Y. Fenard, Y. Ju, Uncertainty assessment of species measurements in acetone counterflow diffusion flames, Proc. Combust. Inst. 34 (2013) 813-820. [30] T. Ombrello, S.H. Won, Y. Ju, S. Williams, Flame propagation enhancement by plasma excitation of oxygen. Part I: Effects of $\mathrm{O}_{3}$, Combust. Flame 157 (2010) 1906-1915. [31] X. Qin, Y. Ju, Measurements of burning velocities of dimethyl ether and air premixed flames at elevated pressures, Proc. Combust. Inst. 30 (2005) 233-240. [32] D. Liu, J. Santner, C. Togbé, D. Felsmann, J. Koppmann, A. Lackner, X. Yang, X. Shen, Y. $\mathrm{Ju}, \mathrm{K}$. Kohse-Höinghaus, Flame structure and kinetic studies of carbon dioxide-diluted dimethyl ether flames at reduced and elevated pressures, Combust. Flame 160 (2013) 2654-2668. [33] U. Niemann, K. Seshadri, F.A. Williams, Accuracies of laminar counterflow flame experiments, Combust. Flame 162 (2015) 1540-1549.

[34] J.E. Harrington, K.C. Smyth, Laser-induced fluorescence measurements of formaldehyde in a methane/air diffusion flame, Chem. Phys. Lett. 202 (1993) 196-202.

[35] R.J. Kee, J.F. Grcar, M.D. Smooke, J.A. Miller, E. Meeks, PREMIX: A Fortran program for modeling steady laminar one-dimensional premixed flames, Report No. SAND85-8240, Sandia National Laboratories, Livermore, CA, 1985.

[36] Y. Ju, H. Guo, K. Maruta, F. Liu, On the extinction limit and flammability limit of nonadiabatic stretched methane-air premixed flames, J. Fluid Mech. 342 (1997) 315-334. [37] Z. Zhao, M. Chaos, A. Kazakov, F.L. Dryer, Thermal decomposition reaction and a comprehensive kinetic model of dimethyl ether, Int. J. Chem. Kinet. 40 (2008) 1-18. [38] L.B. Ibraguimova, G.D. Smekhov, O.P. Shatalov, "Recommended rate constants of chemical reactions in an $\mathrm{H}_{2}-\mathrm{O}_{2}$ gas mixture with electronically excited species $\mathrm{O}_{2}\left({ }^{1} \Delta\right), \mathrm{O}\left({ }^{1} \mathrm{D}\right)$, $\mathrm{OH}\left({ }^{2} \Sigma\right)$ involved," Institute of Mechanics of Lomonosov, Moscow State University, 2003. [39] Y. Ju, W. Sun, Plasma assisted combustion: Dynamics and chemistry, Prog. Energy Combust. Sci. 48 (2015) 21-83.

[40] P. Zhao, W. Liang, S. Deng, C.K. Law, On premixed cool flames in the counterflow, 9th U.S. National Combustion Meeting (2015), paper 3E01. 


\section{Figure Captions}

Fig. 1. A simplified schematic of the experiment's counterflow burner in the premixed configuration. $L$ represents the distance between the upper and lower burners $(2.25 \mathrm{~cm})$.

Fig. 2. Direct photographs of (a) a premixed cool flame and (b) a premixed hot flame at identical equivalence ratios of $\phi=0.114$ and strain rates of $a=89 \mathrm{~s}^{-1}$. For both photographs, the shutter speed is one second.

Fig. 3. S-curve calculation for a $\mathrm{DME} / \mathrm{O}_{2} / \mathrm{O}_{3}$ mixture at $\phi=0.114$, which matches the experimental conditions of Figs. $2 \mathrm{a}$ and $2 \mathrm{~b}$.

Fig. 4. S-curve calculations for a $\mathrm{DME} / \mathrm{O}_{2} / \mathrm{O}_{3}$ mixture at three different equivalence ratios, showing the impact of fuel concentration on hot and cool flame extinction.

Fig. 5. Flame regime diagram for $\mathrm{DME} / \mathrm{O}_{2} / \mathrm{O}_{3}$ mixtures with both experimental and numerical modeling results included.

Fig. 6. S-curve calculation for a $\mathrm{DME} / \mathrm{O}_{2} / \mathrm{O}_{3}$ mixture at $\phi=0.08$, depicting the hysteresis possible between hot flames and cool flames at low equivalence ratios.

Fig. 7. Rate constant sensitivity analysis for the ignition (LTI, HTI) and extinction (CFE, HFE) strain rates of a $\mathrm{DME} / \mathrm{O}_{2} / \mathrm{O}_{3}$ mixture at $\phi=0.08$.

Fig. 8. Raw $\mathrm{CH}_{2} \mathrm{O}$ PLIF images of (a) a premixed cool flame and (b) a premixed hot flame at the same experimental conditions as Figs. $2 \mathrm{a}$ and $2 \mathrm{~b}\left(\phi=0.114, a=89 \mathrm{~s}^{-1}\right)$. The laser sheet is entering from the right side of the images.

Fig. 9. (a) Centerline $\mathrm{CH}_{2} \mathrm{O}$ PLIF signal for the cool flame and hot flame in Figs. 7a and 7b. (b) Calculated $\mathrm{CH}_{2} \mathrm{O}$ mole fraction and heat release rate for a cool flame and hot flame at the same experimental conditions ( $\left.\phi=0.114, a=89 \mathrm{~s}^{-1}\right)$. The top burner nozzle is located at $0.0 \mathrm{~cm}$, and the bottom burner nozzle is at $2.25 \mathrm{~cm}$.

Fig. 10. Centerline $\mathrm{CH}_{2} \mathrm{O}$ PLIF signal (experiment) and $\mathrm{CH}_{2} \mathrm{O}$ mole fraction (calculated) for a cool flame at $\phi=0.088$ and $a=89 \mathrm{~s}^{-1}$.

Fig. 11. Dependence of flame position (measured by the centerline $\mathrm{CH}_{2} \mathrm{O}$ PLIF maximum value) on equivalence ratio for cool flames and hot flames. The top burner nozzle is located at $0.0 \mathrm{~cm}$, and the bottom burner nozzle is at $2.25 \mathrm{~cm}$. The $a=58 \mathrm{~s}^{-1}$ and $76 \mathrm{~s}^{-1}$ points are momentum imbalanced. 


\section{FIGURES}

Figure 1

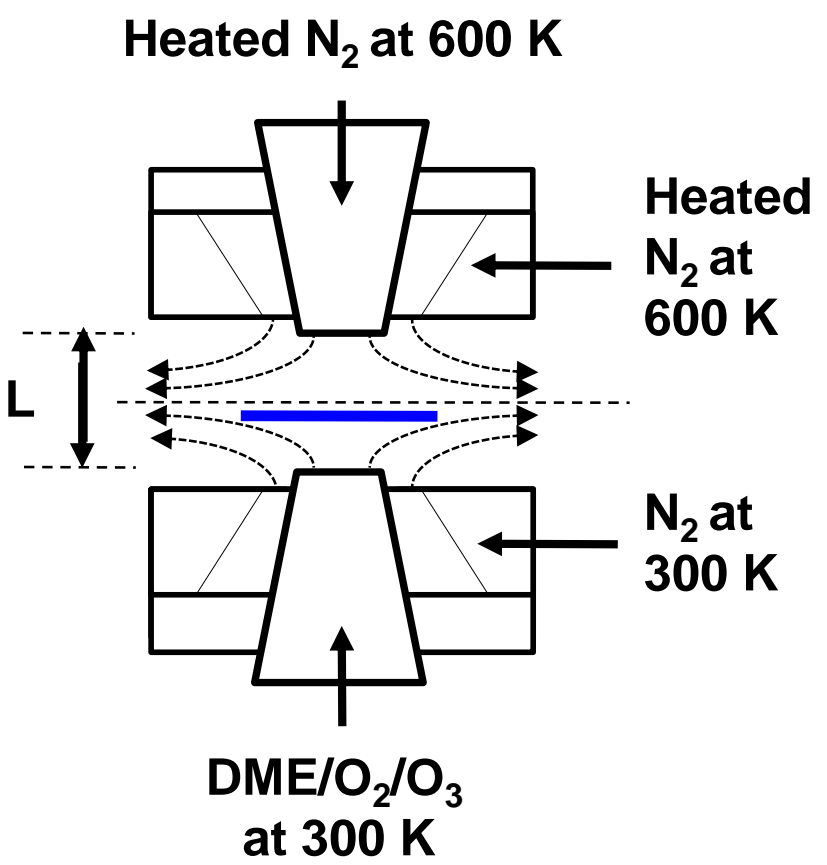


Figure 2
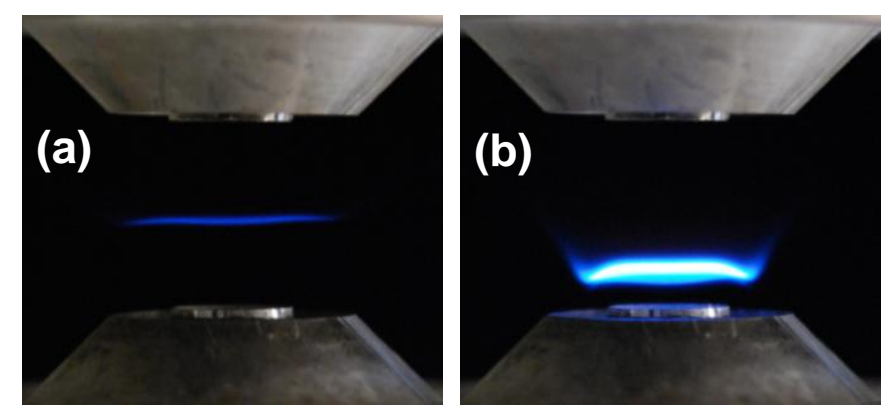
Figure 3

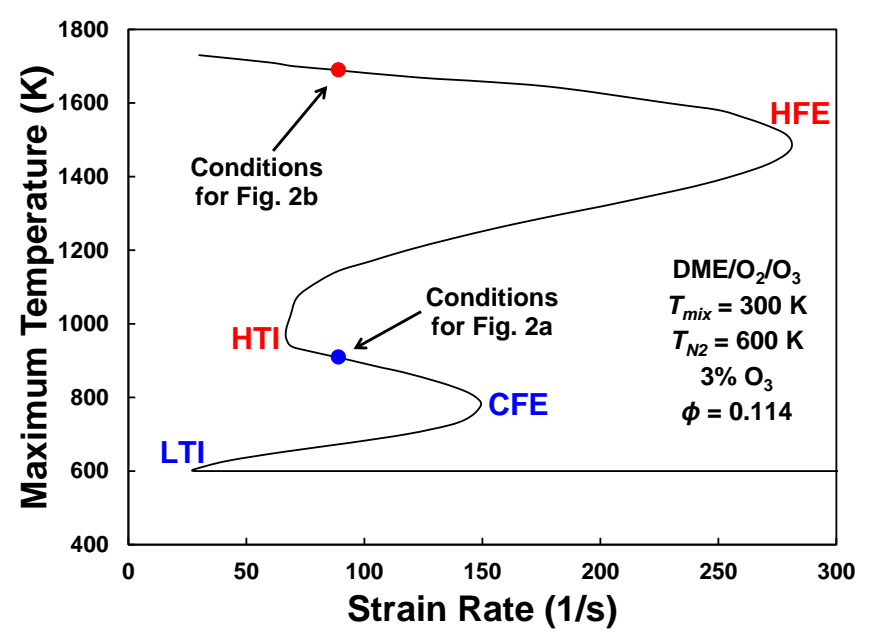

23

24

25 
Figure 4

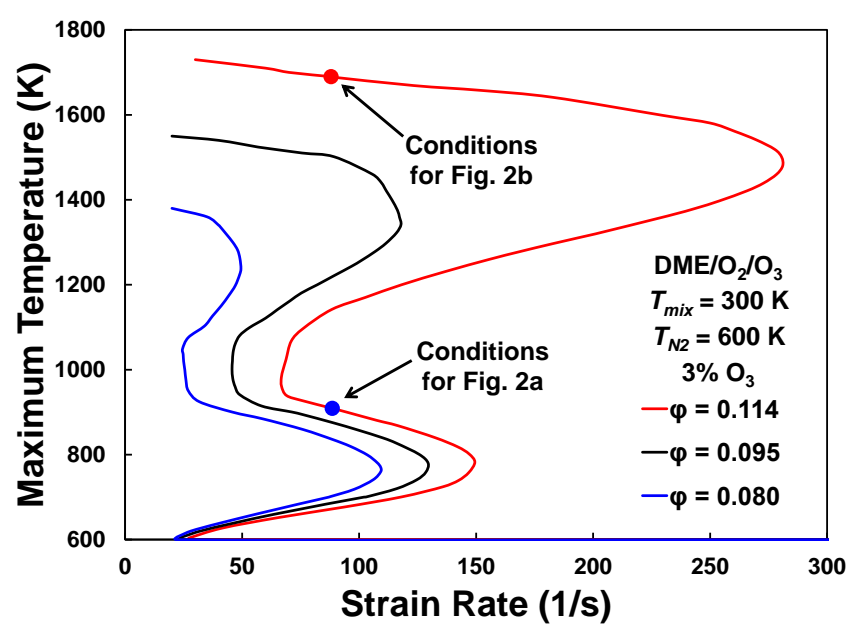


Figure 5

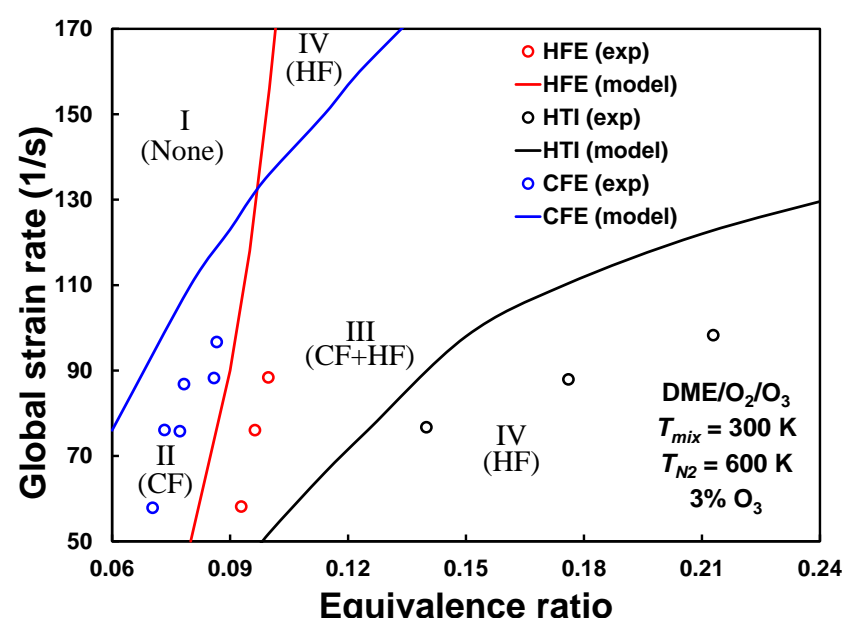




\section{Figure 6}

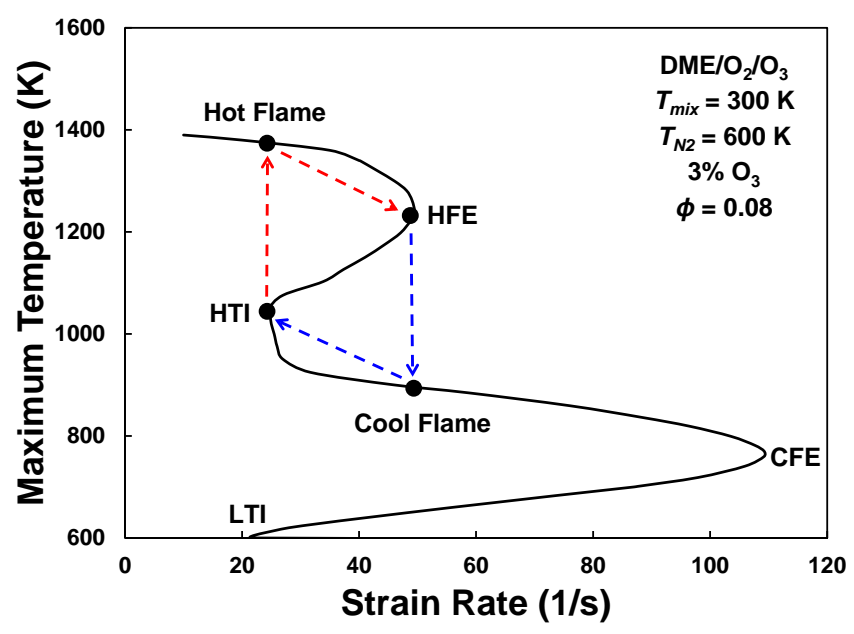


Figure 7

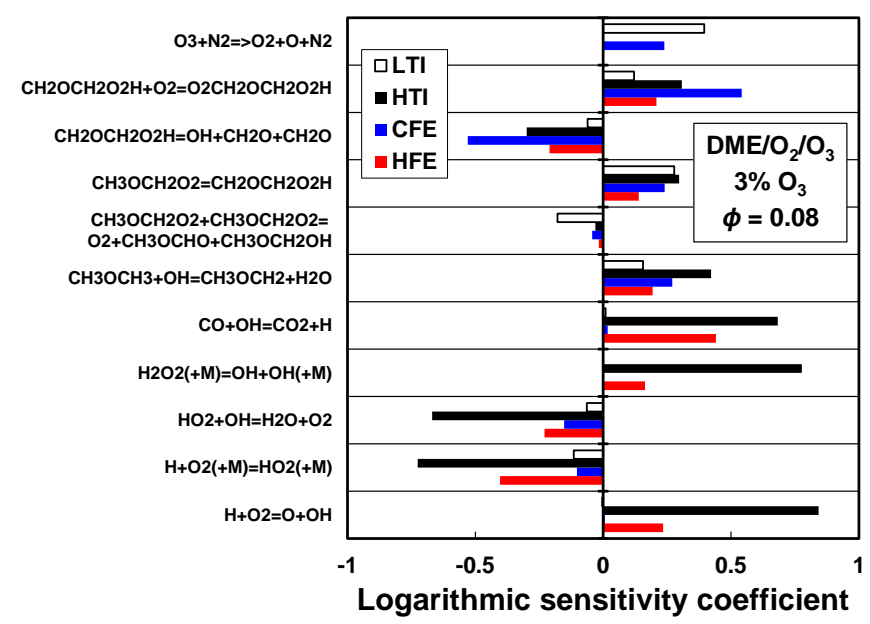




\section{Figure 8}

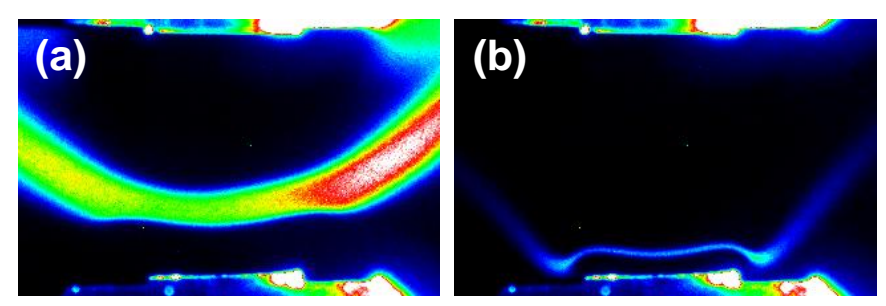




\section{Figure 9}
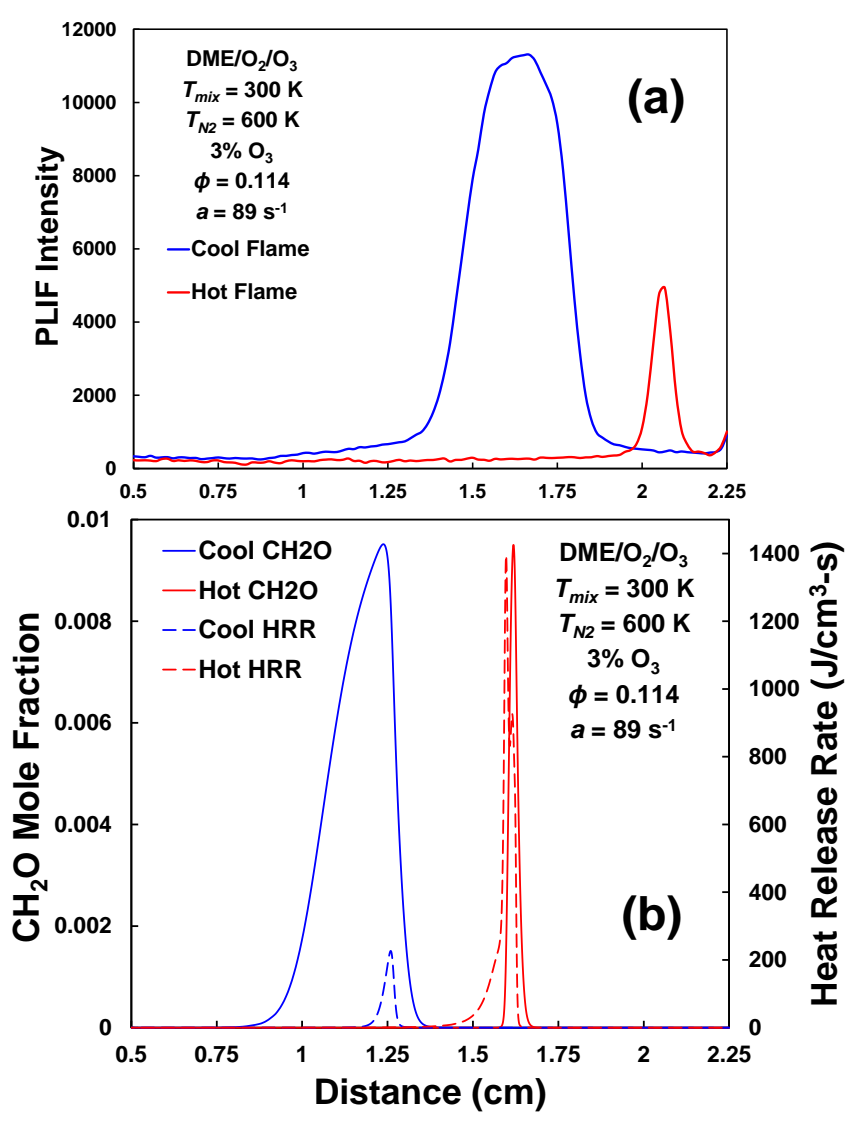
Figure 10

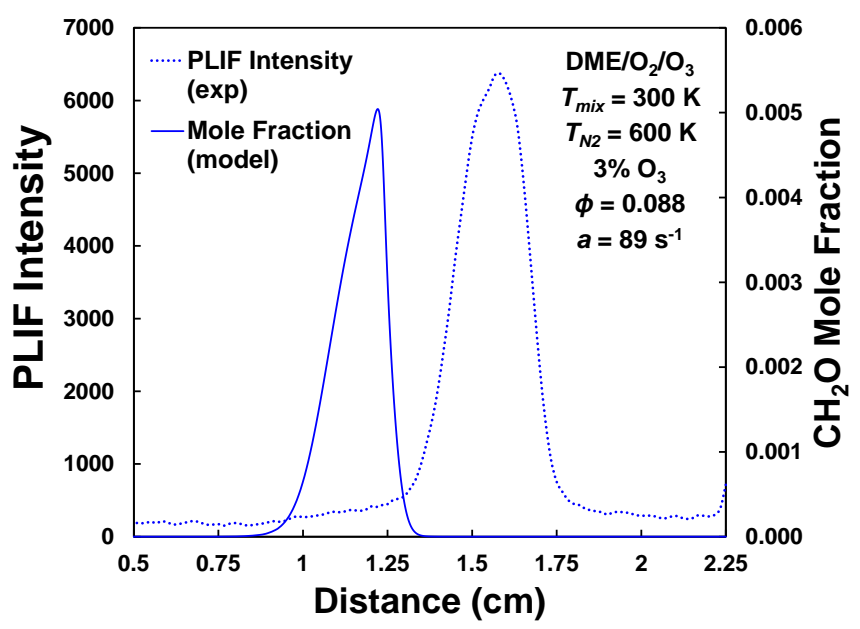


Figure 11

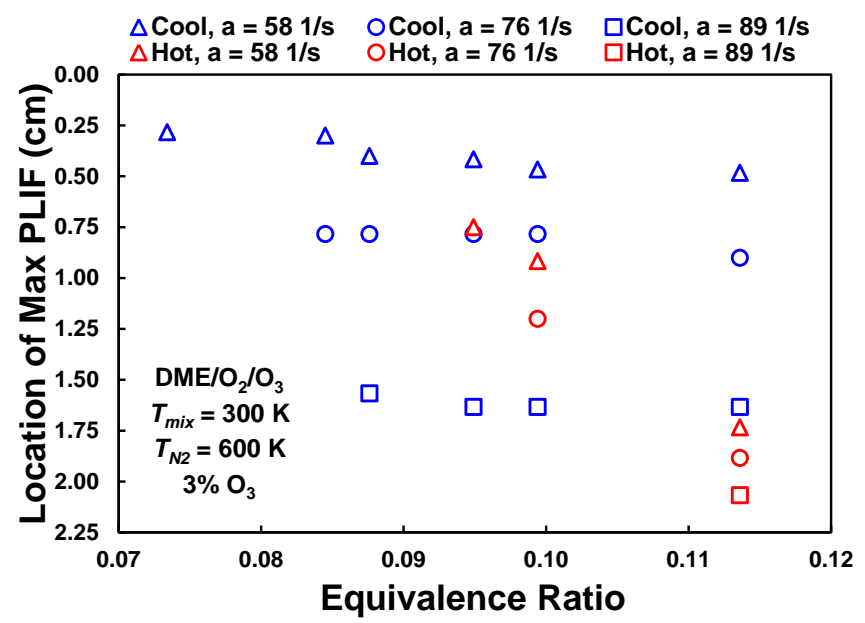

